\title{
Inflammoscopy in the diagnosis of hypertrophic lichen planus
}

\author{
Virgínia Coelho de Sousa, MD, and André Oliveira, MD \\ Lisboa, Portugal
}

\section{CLINICAL PRESENTATION}

A 43-year-old woman presented with a 2-year history of pruritic, thick, brown, hyperkeratotic plaques located on the legs (Fig 1).

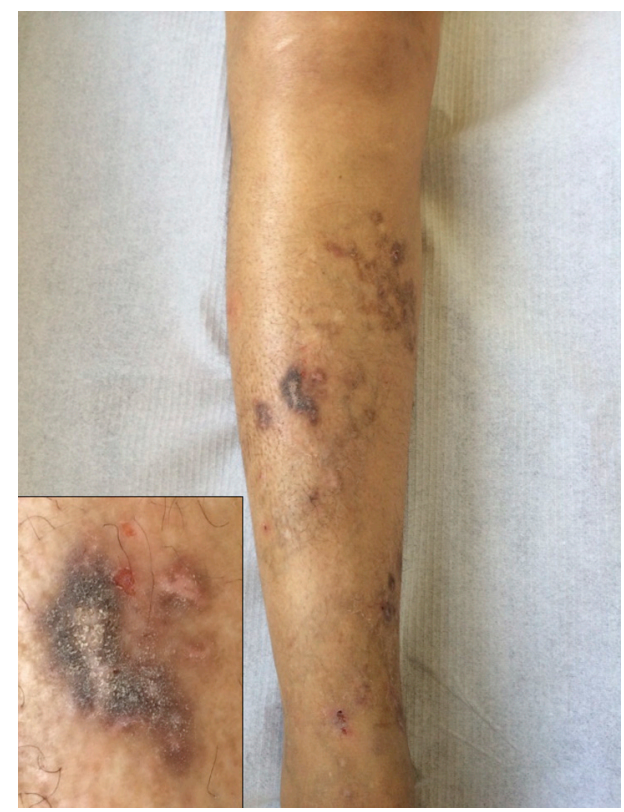

Fig 1. Clinical presentation of hypertrophic lichen planus. Hyperkeratotic, pigmented plaques on the shins, with small areas of dyspigmentation, admixed with patches of postinflammatory hyperpigmentation. Accentuated follicular induration and chalklike scale were also observed (inset image).

\section{DERMOSCOPIC APPEARANCE}

Round and reticular whitish structures, some with thin arboriform projections were seen using contact, dry dermoscopy. The use of alcohol as immersion liquid found multiple large comedolike openings filled with round, yellowish keratin material, resembling oil drops within a brown background. Chalk-white structureless areas were also observed (Fig 2).

From the Department of Dermatology, Hospital de Curry Cabral-Centro Hospitalar de Lisboa Central.

Funding sources: None.

Conflicts of interest: None declared.

Correspondence to: André Oliveira, MD, Department of

Dermatology, Hospital Santo António dos Capuchos - Centro
Hospitalar de Lisboa Central, Lisboa, Portugal. E-mail: andre. oliveira@sapo.pt.

J Am Acad Dermatol 2015;73:e171-3.

0190-9622/\$36.00

(c) 2015 by the American Academy of Dermatology, Inc.

http://dx.doi.org/10.1016/j.jaad.2015.07.025 

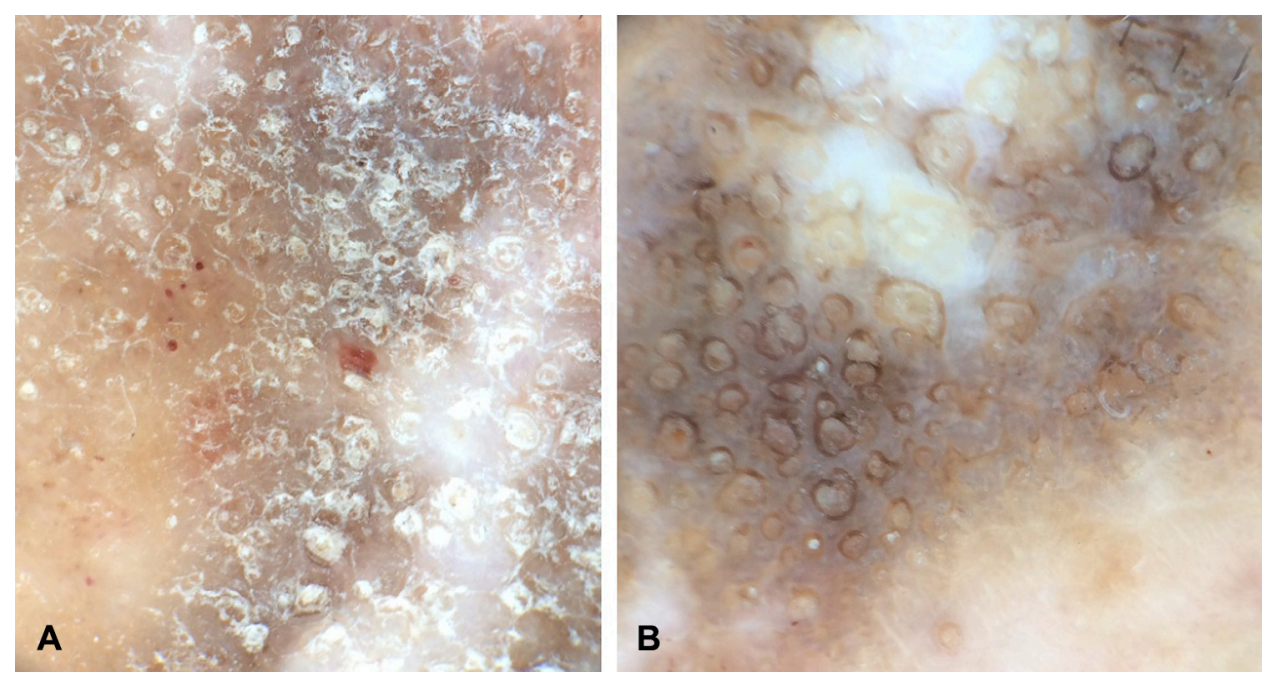

Fig 2. Dermoscopic appearance of hypertrophic lichen planus. A, Round and reticular white structures correspond with Wickham striae better seen using dry dermoscopy. B, The use of alcohol as immersion liquid allowed the observation of multiple large comedolike openings filled with yellowish material and chalk-white structureless areas. (Original magnification: A and $\mathbf{B}, \times 10$.)

\section{HISTOLOGIC DIAGNOSIS}

The diagnosis of hypertrophic lichen planus (HLP) was considered after clinical and dermoscopic correlation. A punch biopsy was then performed. Histopathologic examination found a marked hyperkeratosis and irregular acanthosis, compact orthokeratosis, focal hypergranulosis with follicular dilatation and plugging, and a superficial dense bandlike infiltrate (Fig 3). These features supported the diagnosis of HLP.
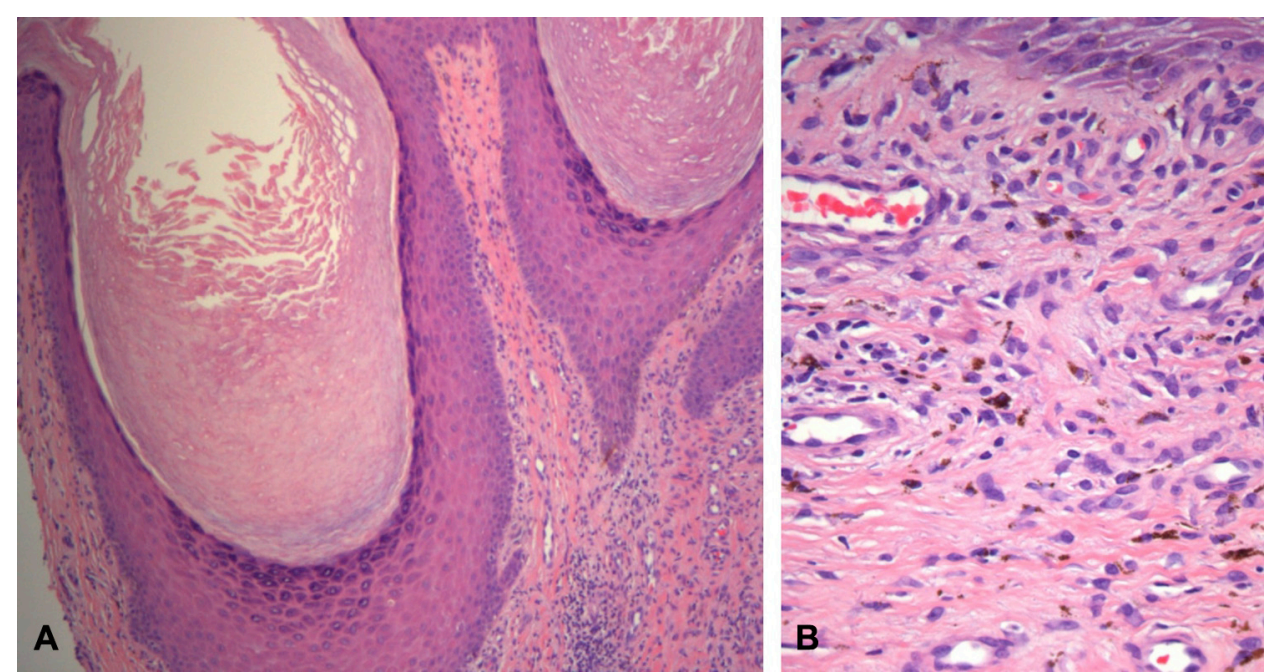

Fig 3. Histopathologic examination of hypertrophic lichen planus. A, Hypergranulosis with follicular dilatation, which corresponds with the comedolike structures found in dermoscopy; a superficial dense bandlike infiltrate is also seen. B. Melanophages in the upper dermis as a result of pigment incontinence may correlate with the dermoscopic brown background. (A and $\mathbf{B}$, hematoxylin-eosin stain; original magnifications: $\mathbf{A}$ and $\mathbf{B}, \times 200$.) 


\section{KEY MESSAGE}

Dermoscopy is a fast and noninvasive technique, increasingly applied in the diagnosis of a broad range of inflammatory skin diseases (inflammoscopy). ${ }^{1}$ In our case, dermoscopic features of HLP were described. Reticular white structures correspond with Wickham striae, resulting from compact orthokeratosis and acanthosis. Large comedolike openings correlate with hypergranulosis of enlarged follicular infundibulum. Absence of specific dermoscopic vascular patterns and yellow scales also allowed the exclusion of chronic dermatitis.

Inflammoscopy can, therefore, contribute to the early recognition and treatment of HLP, which is important considering the possible development of squamous cell carcinoma in longstanding, nontreated lesions, ${ }^{2}$ hence, its possible role also in the monitoring of these patients.

\section{REFERENCES}

1. Lallas A, Zalaudek I, Argenziano G, et al. Dermoscopy in general Dermatology. Dermatol Clin. 2013;31:679-694.

2. Singh SK, Saikia UN, Ajith C, Kumar B. Squamous cell carcinoma arising from hypertrophic lichen planus. J Eur Acad Dermatol Venereol. 2006;20:745-746. 